\title{
The challenge of the dementias
}

Citation for published version (APA):

Eastwood, R., Amaducci, L., Brayne, C., Broc, T., \& Jolles, J. (1996). The challenge of the dementias. Lancet, 347(9011), 1303-1307. https://doi.org/10.1016/S0140-6736(96)90943-5

Document status and date:

Published: 01/01/1996

DOI:

10.1016/S0140-6736(96)90943-5

Document Version:

Publisher's PDF, also known as Version of record

\section{Please check the document version of this publication:}

- A submitted manuscript is the version of the article upon submission and before peer-review. There can be important differences between the submitted version and the official published version of record.

People interested in the research are advised to contact the author for the final version of the publication, or visit the DOI to the publisher's website.

- The final author version and the galley proof are versions of the publication after peer review.

- The final published version features the final layout of the paper including the volume, issue and page numbers.

Link to publication

\footnotetext{
General rights rights.

- You may freely distribute the URL identifying the publication in the public portal. please follow below link for the End User Agreement:

www.umlib.nl/taverne-license

Take down policy

If you believe that this document breaches copyright please contact us at:

repository@maastrichtuniversity.nl

providing details and we will investigate your claim.
}

Copyright and moral rights for the publications made accessible in the public portal are retained by the authors and/or other copyright owners and it is a condition of accessing publications that users recognise and abide by the legal requirements associated with these

- Users may download and print one copy of any publication from the public portal for the purpose of private study or research.

- You may not further distribute the material or use it for any profit-making activity or commercial gain

If the publication is distributed under the terms of Article $25 \mathrm{fa}$ of the Dutch Copyright Act, indicated by the "Taverne" license above, 


\title{
The challenge of the dementias
}

\author{
Writing Committee, Lancet conference 1996*
}

Cognitive decline is a common feature of ageing, sometimes gentle at other times less so. It manifests as a wide spectrum from cognitive impairment that is not dementia to Alzheimer's disease and to the much rarer but potentially enlightening familial forms. The Lancet's 1996 international conference was held in Edinburgh, UK, on April 25 and 26. The meeting brought together epidemiologists, geneticists, neuropsychologists, neuropathologists, clinicians, and imaging specialists, and those concentrating on the social and ethical aspects of the dementias. Half the conference was devoted to discussion that crossed specialty boundaries. This report highlights the major areas of agreement and controversy and points to opportunities for future multidisciplinary research.

The spectrum of cognitive impairment is addressed in four main areas, following the conference format-namely, Epidemiology; Genetics and Biomarkers; Neuroimaging, Neuropsychology, and Neuropathology; and Social Aspects. Selected references are provided for further background reading.

\section{Epidemiology}

Many studies have investigated the prevalence of dementia in the community. ${ }^{1-3}$ Once case-finding criteria were standardised in the early $1980 \mathrm{~s}$, the population prevalence of senile dementia above age 65 was consistently reported to be about $5 \%$. Yet, despite the vast amount of data generated from prevalence, case-control and incidence investigations, key epidemiological questions await answers from studies now in progress. In particular:

- What is the nature and prevalence of subtle degrees of cognitive impairment (cognitive impairment no dementia, CIND) as opposed to overt dementia? ${ }^{4}$

- What is the incidence of dementia/cognitive impairment in the oldest old?

- What differences in incidence and prevalence exist across different cultures, and why?

- How will the general-ie, cohort-effects of cardiovascular and cerebrovascular risk reduction influence future rates of cognitive impairment?

The most pressing issue is our remarkable lack of understanding about the natural history of cognitive decline. Is cognitive deterioration a continuous, agerelated process or is it a discrete disease pathology?5 Underlying this research question is a more profound, almost philosophical issue: what is normal ageing?

Knowledge about natural history demands longitudinal study designs. The rapid acceleration in our understanding of the genetics and neuropathology of the dementias has enabled investigators to correlate age at onset, socio-demographic variables, and symptoms with data from psychometric and genetic testing, neuroimaging, neuropathological examination, and

Lancet 1996; 347: 1303-07

* Members listed at end of article

Correspondence to: Dr M Robin Eastwood, Department of Psychlatry, Saint Louis University, Health Sciences Center, 1221 S Grand Boulevard, Saint Louis, MO 630104, USA response to treatment. Practical measures of cognitive decline must be built into such a research programme. It is not enough to base natural history studies on a series of abstract psychometric or biological variables if they have little or no meaning in the functional realities-eg, activities of daily living - for the persons concerned. Such a programme is likely to require international collaboration and pooling of resources.

This phenomenological approach should have two further benefits. First, it will move the debate beyond existing, and constraining, notions of dementia towards a more empirically governed view of cognitive impairment. Alzheimer's disease and "vascular dementia" imply independent and mutually exclusive disease patterns. This conception of the dementias is now untenable. For example, Skoog et $\mathrm{al}^{6}$ have recently shown the importance of hypertension - a critical vascular risk factor-before the time of onset of disability in patients with a diagnosis of Alzheimer's disease. Second, research into natural history will overcome the limitations of cross-sectional studies that identify risk factors for dementia (see table 1) but which cannot tease out either temporal effects or the complex interactions between risk factors. The temporal sequence in cognitive change is important since noncognitive prodromal or coexisting symptoms of anxiety, depression, or delusions may lead to diagnostic confusion and are themselves treatable. Vulnerability factors-eg, blood pressure and other biological life events-must also be distinguished from potential protective factors, such as $A P O E-\varepsilon 2$ genotype, educational achievement, ongoing intellectual activity, oestrogen, and use of non-steroidal anti-inflammatory drugs.

Investigators also face several methodological obstacles. For instance, the stability over time of the instruments used to measure cognitive decline from psychometric testing, with the risk of substantial learning effects, to

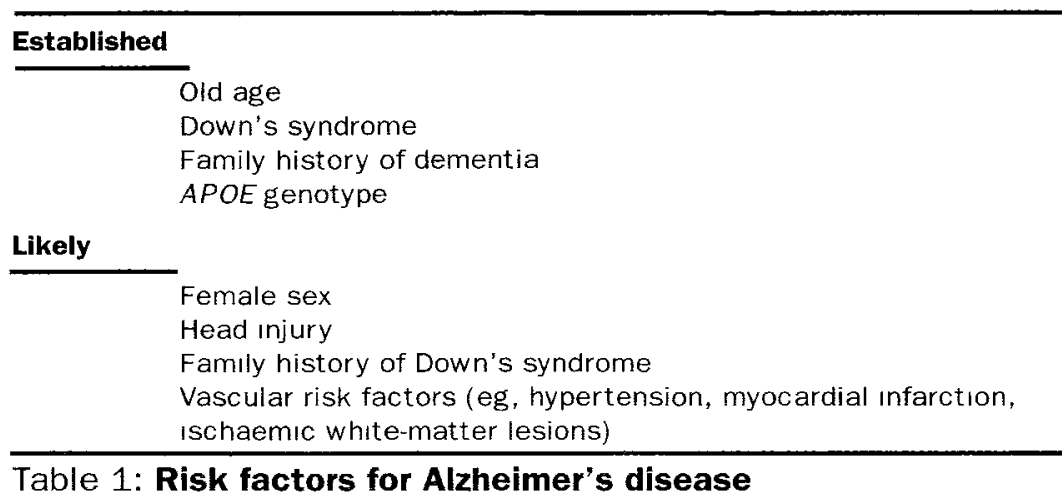


Panel 1: Intervention strategles to limit cognitive impairment Cognitive function exists as a continuum. The high-risk approach aims to treat a small proportion of high-risk individuals (shaded) to shift their cognitive function to within "normal" limits. A population strategy aims to reduce the risk of the whole population.

\section{High-risk strategy}

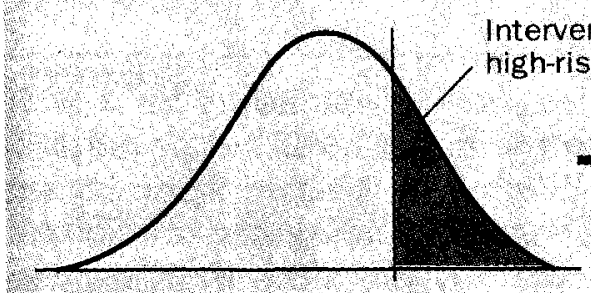

Cognitive function tervention for

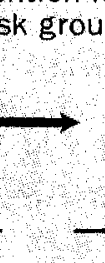

Cognitive function
Population strategy

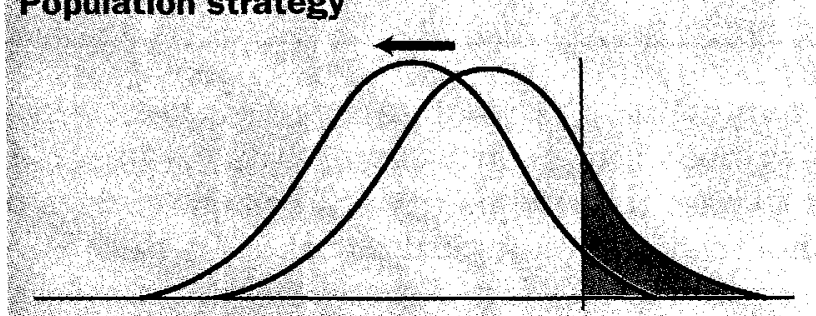

Cognitive function

neuropathological grading is largely unknown. And measurement error is an often unacknowledged but important source of bias. There is also a tension between the needs of researchers and clinicians. Those conducting research will wish to avoid labelling patients, but physicians (and their patients) need these diagnostic categories to advise, counsel, and plan management strategies.

Observational epidemiology will provide the foundation for intervention strategies. Two approaches are possible (see panel 1). First, a high-risk strategy will require an effective drug to reduce the rate of cognitive decline. The major research initiative in drug therapy for Alzheimer's disease still lies in developing agents to influence cerebral cholinergic systems-eg, acetylcholinesterase inhibitors and selective cholinergic agonists. An attractive alternative approach is to modify overall population risk--eg, by antihypertensive therapy.

However, before randomised clinical trials can proceed, there are substantial difficulties in study design to be resolved. For example, what should be the appropriate primary outcome measures to judge efficacy? Improved functional performance, to be sure, but other variables such as imaging end-points may also be important. How does one estimate a likely size effect of a given treatment? How should one stratify the study population? By genotype or with other variables-eg, age at onset, blood pressure, or educational level? And how will trialists address informed consent in a population with perhaps severe cognitive impairment? Two stages to a clinical trial programme are likely. First, there will be smaller exploratory trials with strict eligibility criteria, which aim to gather data on efficacy. These studies will be driven by hypotheses generated from longitudinal surveys. Second, larger, more pragmatic clinical trials will follow. These will have wide inclusion criteria and will look at effectiveness, acceptability, compliance, and cost. It is likely to be some time before these larger trials will be warranted.

\section{References}

1 Amaducci LA, Fratiglioni L, Rocca WA et al. Risk factors for clinically diagnosed Alzheimer's disease. Neurology 1986; 36: 922-31.

2 Jorm A F, Korten A E, Henderson A S. The prevalence of dementra: a quantitative integration of the literature. Acta Psychiatr Scand 1987; 76: 456-79.

3 Canadian Study of Health and Aging Working Group. Canadian study of health and aging : study methods and prevalence of dementia. Can Med Assoc F 1994; 150: 899-913.

4 Brayne C, Gill C, Paykel E S et al. Cognitive decline in an elderly population a two wave study of change. Psych Med 1995; 25: 673-83.

5 Khaw K-T. Public health implications of a continuum model of dementia. In: Huppert FA, Brayne C, O'Connor DW, eds. Dementia and normal aging. Cambridge: Cambridge University Press, 1994 chap 23.

6 Skoog I, Levnfelt B, Landahl S et al. 15-year longitudinal study of blood pressure and dementia. Lancet 1996; 347: 1141-45.

\section{Genetics and biomarkers}

There is more to the genetics of Alzheimer's disease than the susceptibility allele $A P O E-\varepsilon 4$, and it seems inevitable that other susceptibility genes and, possibly, other autosomal dominant genes will be found. Those we know about are summarised in panel 2 , and are reviewed elsewhere. ${ }^{6}$

The current position on the place of $A P O E$ genotyping-_maybe" to using it to assist in an already suspected diagnosis of Alzheimer's but "no" to its use to screen healthy individuals for future risk-has been recently summarised in a consensus statement. ${ }^{1}$

The discovery of autosomal dominant gene mutations in familial Alzheimer's disease has excited research workers not because they explain a high proportion of dementia but because, once the functions of the normal gene products are known, light may be thrown on biological mechanisms of Alzheimer's disease-therapeutic targets being the ultimate objective. Their scientific contribution may thus be out of proportion to the incidence of the mutations-as happened with the Li-Fraumeni cancer syndrome and p53, for example.

Molecular genetics (in families) and population genetics is a complementary process in Alzheimer's disease-as it has proved to be in the genetics of breast cancer and TaySachs disease. Clinicians should be encouraged to ask about family size and history in patients with dementia. They must be attuned to picking up familial aggregations (research indicates that close to $50 \%$ of Alzheimer cases have at least one first-degree relative with dementia). New susceptibility genes/factors will probably be found but they

Panel 2: Familial Alzheimer's disease genes and other genetic influences

APP $=$ amyloid precursor protein. ${ }^{2}$ On chromosome $21 ;$ autosomal dominant; four mutations identified so far. Early onset (40-65 years); 20 families known to date.

PS-1 (or \$182) = presenilin-1. ${ }^{3}$ On chromosome 14; autosomal dominant; 28 mutations. Early onset (30-55); less than 100 families.

PS-2 (or STM2) = presenilin-2. ${ }^{4}$ On chromosome 1; autosomal dominant with variable penetrance; three mutations. Wide range of age of onset (40-90); three big families, one being the Volga-German kindreds.

APOE $=$ apolipoprotein-E. ${ }^{5}$ On chromosome 19; three common polymorphisms known as alleles $\varepsilon 2, \varepsilon 3$, and $\varepsilon 4$ ( $\varepsilon 1$ is very rare). Possession of one or two $\varepsilon 4$ alleles certainly a risk factor for Alzheimer's disease; $\varepsilon 2$ probably protective. Age of onset from 40 to very old age. 
Panel 1: Intervention strategles to limit cognitive impairment Cognitive function exists as a continuum. The high-risk approach aims to treat a small proportion of high-risk individuals (shaded) to shift their cognitive function to within "normal" limits. A population strategy aims to reduce the risk of the whole population.

\section{High-risk strategy}

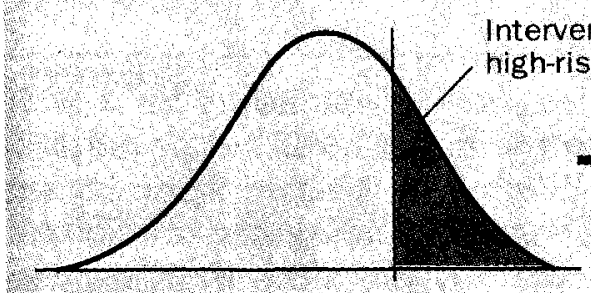

Cognitive function tervention for

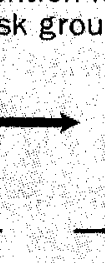

Cognitive function
Population strategy

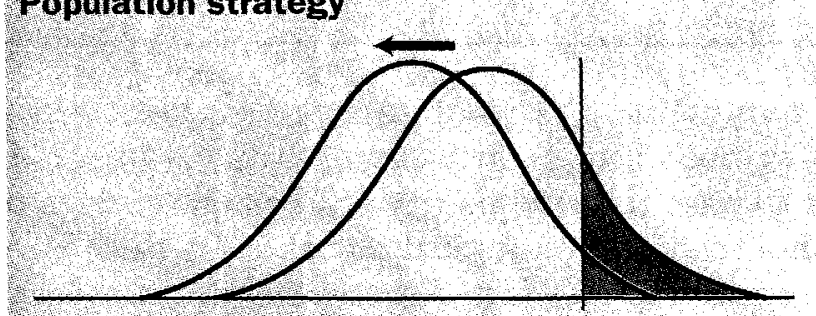

Cognitive function

neuropathological grading is largely unknown. And measurement error is an often unacknowledged but important source of bias. There is also a tension between the needs of researchers and clinicians. Those conducting research will wish to avoid labelling patients, but physicians (and their patients) need these diagnostic categories to advise, counsel, and plan management strategies.

Observational epidemiology will provide the foundation for intervention strategies. Two approaches are possible (see panel 1). First, a high-risk strategy will require an effective drug to reduce the rate of cognitive decline. The major research initiative in drug therapy for Alzheimer's disease still lies in developing agents to influence cerebral cholinergic systems-eg, acetylcholinesterase inhibitors and selective cholinergic agonists. An attractive alternative approach is to modify overall population risk--eg, by antihypertensive therapy.

However, before randomised clinical trials can proceed, there are substantial difficulties in study design to be resolved. For example, what should be the appropriate primary outcome measures to judge efficacy? Improved functional performance, to be sure, but other variables such as imaging end-points may also be important. How does one estimate a likely size effect of a given treatment? How should one stratify the study population? By genotype or with other variables-eg, age at onset, blood pressure, or educational level? And how will trialists address informed consent in a population with perhaps severe cognitive impairment? Two stages to a clinical trial programme are likely. First, there will be smaller exploratory trials with strict eligibility criteria, which aim to gather data on efficacy. These studies will be driven by hypotheses generated from longitudinal surveys. Second, larger, more pragmatic clinical trials will follow. These will have wide inclusion criteria and will look at effectiveness, acceptability, compliance, and cost. It is likely to be some time before these larger trials will be warranted.

\section{References}

1 Amaducci LA, Fratiglioni L, Rocca WA et al. Risk factors for clinically diagnosed Alzheimer's disease. Neurology 1986; 36: 922-31.

2 Jorm A F, Korten A E, Henderson A S. The prevalence of dementra: a quantitative integration of the literature. Acta Psychiatr Scand 1987; 76: 456-79.

3 Canadian Study of Health and Aging Working Group. Canadian study of health and aging : study methods and prevalence of dementia. Can Med Assoc F 1994; 150: 899-913.

4 Brayne C, Gill C, Paykel E S et al. Cognitive decline in an elderly population a two wave study of change. Psych Med 1995; 25: 673-83.

5 Khaw K-T. Public health implications of a continuum model of dementia. In: Huppert FA, Brayne C, O'Connor DW, eds. Dementia and normal aging. Cambridge: Cambridge University Press, 1994 chap 23.

6 Skoog I, Levnfelt B, Landahl S et al. 15-year longitudinal study of blood pressure and dementia. Lancet 1996; 347: 1141-45.

\section{Genetics and biomarkers}

There is more to the genetics of Alzheimer's disease than the susceptibility allele $A P O E-\varepsilon 4$, and it seems inevitable that other susceptibility genes and, possibly, other autosomal dominant genes will be found. Those we know about are summarised in panel 2 , and are reviewed elsewhere. ${ }^{6}$

The current position on the place of $A P O E$ genotyping-_maybe" to using it to assist in an already suspected diagnosis of Alzheimer's but "no" to its use to screen healthy individuals for future risk-has been recently summarised in a consensus statement. ${ }^{1}$

The discovery of autosomal dominant gene mutations in familial Alzheimer's disease has excited research workers not because they explain a high proportion of dementia but because, once the functions of the normal gene products are known, light may be thrown on biological mechanisms of Alzheimer's disease-therapeutic targets being the ultimate objective. Their scientific contribution may thus be out of proportion to the incidence of the mutations-as happened with the Li-Fraumeni cancer syndrome and p53, for example.

Molecular genetics (in families) and population genetics is a complementary process in Alzheimer's disease-as it has proved to be in the genetics of breast cancer and TaySachs disease. Clinicians should be encouraged to ask about family size and history in patients with dementia. They must be attuned to picking up familial aggregations (research indicates that close to $50 \%$ of Alzheimer cases have at least one first-degree relative with dementia). New susceptibility genes/factors will probably be found but they

Panel 2: Familial Alzheimer's disease genes and other genetic influences

APP $=$ amyloid precursor protein. ${ }^{2}$ On chromosome $21 ;$ autosomal dominant; four mutations identified so far. Early onset (40-65 years); 20 families known to date.

PS-1 (or \$182) = presenilin-1. ${ }^{3}$ On chromosome 14; autosomal dominant; 28 mutations. Early onset (30-55); less than 100 families.

PS-2 (or STM2) = presenilin-2. ${ }^{4}$ On chromosome 1; autosomal dominant with variable penetrance; three mutations. Wide range of age of onset (40-90); three big families, one being the Volga-German kindreds.

APOE $=$ apolipoprotein-E. ${ }^{5}$ On chromosome 19; three common polymorphisms known as alleles $\varepsilon 2, \varepsilon 3$, and $\varepsilon 4$ ( $\varepsilon 1$ is very rare). Possession of one or two $\varepsilon 4$ alleles certainly a risk factor for Alzheimer's disease; $\varepsilon 2$ probably protective. Age of onset from 40 to very old age. 
have to be evaluated in the light of $A P O E$-genotype-specific distributions of those factors.

Major ways of subdividing clinical phenotypes in Alzheimer's disease include $A P O E$ status and, albeit with less certainty, age of onset. We do not know how much of all dementia is genetic. Classic teaching says no more than $10 \%$. Today, the known susceptibility allele and mutations can explain a higher proportion of Alzheimer's disease. And in non-Alzheimer's dementia we have Huntington's disease and the prion disease as examples with known genetic aetiology.

We do not know what the normal gene products of $A P P$, $P S-1$, and $P S-2$ do-or what, in the brain, apolipoprotein$E$ does or even where it is made. However, there are suggestions - eg, altered processing of amyloid precursor protein $(A P P)$; interference in the "notch" signalling pathway determining cell fate during development, hinted at by sequence homologies in the well-studied worm Caenorhabditis elegans (PS1/2); and calcium homoeostasis.

Research emphases are:

- We must find the other genes-and the functions of those already known.

- We need proper epidemiology, including longitudinal design and necropsy confirmation, to measure relative risks and to determine the sensitivity and specificity of APOE genotyping.

- Future research should emphasise pathological confirmation and investigate the correlates of decline in the brain.
- The case-definition of Alzheimer's disease has served well for 10-12 years but now needs a new look with a view to working diagnoses rather than "gold standards".

- Interactions of $A P O E$ genotype and drug response should be further explored.

- Environmental interactions (eg, with previous head injury and virus infections) have to be investigated.

- Better animal models are needed to study mechanisms and to screen for therapeutic agents. We have a mouse model for amyloid-containing plaques (but no tangles), the "knockout" mouse (for $A P P$ and $A P O E$ ), and a possible model for spontaneous Alzheimer-like neuropathology (Microcebus murinus).

\section{References}

1 National Institute of Aging/Alzheimer's Association Working Group. Apolipoprotein E genotyping in Alzheimer's disease. Lancet 1996; 347: 1091-95.

2 Selkoe DJ. Cell biology of the amyloid beta-protein precursor and the mechanism of Alzheimer's disease. Annu Rev Cell Biol 1994; 10: 373-403.

3 Sherrington R, Rogaev EI, Laing Y, et al. Cloning of a gene bearing missense mutations in early-onset familial Alzheimer's disease. Nature 1995; 375: 754-60.

4 Levy-Lahad E, Wasco W, Poorkaj P, et al. Candidate gene for the chromosome 1 familial Alzheimer's disease locus. Science 1995; 269: 973-77.

5 Roses AD. Apolipoprotein E alleles as risk factors in Alzheimer's disease. Annu Rev Med 1996; 47: 387-400.

6 Busfield F, Goate A. Genetics of Alzheimer's disease. In: Ashall F, Goate A, eds. Pathobiology of Alzheimer's disease. London: Academic Press, 1995: 59-78.

\section{Neuroimaging, neuropsychology, and neuropathology}

For clinicians, the challenge of the dementias begins with the characterisation of normal brain ageing. By means of neuropathological, neuropsychological, and neuroimaging techniques we are now moving towards a definition of normality; without that knowledge, defining a threshold of dementia is impossible.

The effect of age alone is unknown but probably less than has been assumed previously. Our concepts of normal brain ageing have been based on "contaminated" samples of so-called normal elderly individuals -in other words, the control or reference populations have reflected responder and survivor biases and have very probably included subclinical or prodromal cases. ${ }^{1}$ Age is associated with changes in speed-related tasks, but elderly people can compensate successfully. By using various cues and taking a little longer, they can live virtually normal lives. The learning and practice effects have been seriously underestimated.

A severe hindrance to the assessment of normal ageing has been the reliance on cross-sectional data. Longitudinal studies are essential for this purpose, and obtaining data from informants is a key component of any such investigation. ${ }^{2}$ Longitudinal neuroimaging studies

\begin{tabular}{|c|c|c|}
\hline Time 1 & Time 1 & Time 2 \\
\hline & Cognitively intact & Cognitive declıne (\%) \\
\hline No slowing & 119 & $46(39)$ \\
\hline Motor slowing & 22 & $17(77)^{*}$ \\
\hline$\overline{\text { Parkinson's disease }}$ & $\overline{2}$ & $2(100)$ \\
\hline
\end{tabular}

Table 2: Sydney Older Persons Study: motor slowing and cognitive decline at 3-year follow-up

\section{Panel 3: Pathologies causing age-associated cognitive} decline

Prodromal Alzheimer's disease

Multiple subcortical ischaemia/infarction

Age-related non-hypertensive small-vessel disease

Lewy body disease (Lewy bodies are eosinophilic inclusions originally described in idiopathic Parkinson's disease, and also found in elderly persons with no evidence of neuropsychiatric disorder)

"Normal" ageing?

are also essential to distinguish between normal and disease according to rate of change. Such studies can show, for example, hippocampal volume loss with magnetic resonance imaging (MRI) at the pre-dementia stage in those with progressive cognitive decline. At a neuropathological level in normal ageing brains there is no reduction in hippocampal volume by comparison with Alzheimer's disease, or in any cortical volumes or in any grey matter, and no age-related neuronal loss in the hippocampus. The only volume decline in normal ageing is minor loss of frontal white matter. ${ }^{3}$

Although memory changes are the identifier of impairment they are only one component. ${ }^{5}$ Impairment must be measured in relation to decline from previous performance at several levels-meg, behaviour, morphology, motor function, and cognition. A preliminary analysis of the 3-year incidence data on the first 199 individuals followed up in the Sydney Older Persons Study (a random sample of 537 people aged 75 or more) showed that gait ataxia and motor slowing (table 2) were strong predictors of later cognitive decline and dementia. ${ }^{4}$ There is a tendency to consider impairment in terms of discrete diagnoses. Clinically, however, there is an urgent need to consider interactive disorders such as Alzheimer's disease, vascular abnormalities, Lewy body disease, and others. 
have to be evaluated in the light of $A P O E$-genotype-specific distributions of those factors.

Major ways of subdividing clinical phenotypes in Alzheimer's disease include $A P O E$ status and, albeit with less certainty, age of onset. We do not know how much of all dementia is genetic. Classic teaching says no more than $10 \%$. Today, the known susceptibility allele and mutations can explain a higher proportion of Alzheimer's disease. And in non-Alzheimer's dementia we have Huntington's disease and the prion disease as examples with known genetic aetiology.

We do not know what the normal gene products of $A P P$, $P S-1$, and $P S-2$ do-or what, in the brain, apolipoprotein$E$ does or even where it is made. However, there are suggestions - eg, altered processing of amyloid precursor protein $(A P P)$; interference in the "notch" signalling pathway determining cell fate during development, hinted at by sequence homologies in the well-studied worm Caenorhabditis elegans (PS1/2); and calcium homoeostasis.

Research emphases are:

- We must find the other genes-and the functions of those already known.

- We need proper epidemiology, including longitudinal design and necropsy confirmation, to measure relative risks and to determine the sensitivity and specificity of APOE genotyping.

- Future research should emphasise pathological confirmation and investigate the correlates of decline in the brain.
- The case-definition of Alzheimer's disease has served well for 10-12 years but now needs a new look with a view to working diagnoses rather than "gold standards".

- Interactions of $A P O E$ genotype and drug response should be further explored.

- Environmental interactions (eg, with previous head injury and virus infections) have to be investigated.

- Better animal models are needed to study mechanisms and to screen for therapeutic agents. We have a mouse model for amyloid-containing plaques (but no tangles), the "knockout" mouse (for $A P P$ and $A P O E$ ), and a possible model for spontaneous Alzheimer-like neuropathology (Microcebus murinus).

\section{References}

1 National Institute of Aging/Alzheimer's Association Working Group. Apolipoprotein E genotyping in Alzheimer's disease. Lancet 1996; 347: 1091-95.

2 Selkoe DJ. Cell biology of the amyloid beta-protein precursor and the mechanism of Alzheimer's disease. Annu Rev Cell Biol 1994; 10: 373-403.

3 Sherrington R, Rogaev EI, Laing Y, et al. Cloning of a gene bearing missense mutations in early-onset familial Alzheimer's disease. Nature 1995; 375: 754-60.

4 Levy-Lahad E, Wasco W, Poorkaj P, et al. Candidate gene for the chromosome 1 familial Alzheimer's disease locus. Science 1995; 269: 973-77.

5 Roses AD. Apolipoprotein E alleles as risk factors in Alzheimer's disease. Annu Rev Med 1996; 47: 387-400.

6 Busfield F, Goate A. Genetics of Alzheimer's disease. In: Ashall F, Goate A, eds. Pathobiology of Alzheimer's disease. London: Academic Press, 1995: 59-78.

\section{Neuroimaging, neuropsychology, and neuropathology}

For clinicians, the challenge of the dementias begins with the characterisation of normal brain ageing. By means of neuropathological, neuropsychological, and neuroimaging techniques we are now moving towards a definition of normality; without that knowledge, defining a threshold of dementia is impossible.

The effect of age alone is unknown but probably less than has been assumed previously. Our concepts of normal brain ageing have been based on "contaminated" samples of so-called normal elderly individuals -in other words, the control or reference populations have reflected responder and survivor biases and have very probably included subclinical or prodromal cases. ${ }^{1}$ Age is associated with changes in speed-related tasks, but elderly people can compensate successfully. By using various cues and taking a little longer, they can live virtually normal lives. The learning and practice effects have been seriously underestimated.

A severe hindrance to the assessment of normal ageing has been the reliance on cross-sectional data. Longitudinal studies are essential for this purpose, and obtaining data from informants is a key component of any such investigation. ${ }^{2}$ Longitudinal neuroimaging studies

\begin{tabular}{|c|c|c|}
\hline Time 1 & Time 1 & Time 2 \\
\hline & Cognitively intact & Cognitive declıne (\%) \\
\hline No slowing & 119 & $46(39)$ \\
\hline Motor slowing & 22 & $17(77)^{*}$ \\
\hline$\overline{\text { Parkinson's disease }}$ & $\overline{2}$ & $2(100)$ \\
\hline
\end{tabular}

Table 2: Sydney Older Persons Study: motor slowing and cognitive decline at 3-year follow-up

\section{Panel 3: Pathologies causing age-associated cognitive} decline

Prodromal Alzheimer's disease

Multiple subcortical ischaemia/infarction

Age-related non-hypertensive small-vessel disease

Lewy body disease (Lewy bodies are eosinophilic inclusions originally described in idiopathic Parkinson's disease, and also found in elderly persons with no evidence of neuropsychiatric disorder)

"Normal" ageing?

are also essential to distinguish between normal and disease according to rate of change. Such studies can show, for example, hippocampal volume loss with magnetic resonance imaging (MRI) at the pre-dementia stage in those with progressive cognitive decline. At a neuropathological level in normal ageing brains there is no reduction in hippocampal volume by comparison with Alzheimer's disease, or in any cortical volumes or in any grey matter, and no age-related neuronal loss in the hippocampus. The only volume decline in normal ageing is minor loss of frontal white matter. ${ }^{3}$

Although memory changes are the identifier of impairment they are only one component. ${ }^{5}$ Impairment must be measured in relation to decline from previous performance at several levels-meg, behaviour, morphology, motor function, and cognition. A preliminary analysis of the 3-year incidence data on the first 199 individuals followed up in the Sydney Older Persons Study (a random sample of 537 people aged 75 or more) showed that gait ataxia and motor slowing (table 2) were strong predictors of later cognitive decline and dementia. ${ }^{4}$ There is a tendency to consider impairment in terms of discrete diagnoses. Clinically, however, there is an urgent need to consider interactive disorders such as Alzheimer's disease, vascular abnormalities, Lewy body disease, and others. 
The pathologies causing age-associated cognitive decline are shown in panel 3. To regard these as mutually exclusive entities may make for tidy research projects but will do little for real understanding of brain impairment.

The first step for further research is to refine the tools that we already use. Thus:

- Neuropathological assessment should be based on standardised histological criteria. There is good reason for neuropathologists to devise such criteria "blind"-ie, without knowledge of clinical evaluation or results of imaging procedures.

- Similarly for neuropsychology, we need to understand the psychometric properties of the various tests that are commonly used. For example, what is the mini mental state examination really measuring?

- The neuroimaging net needs to be cast more widely to include all brain areas.

- Longitudinal neuropsychological and neuroimaging studies, with neuropathology, are critical, and interactive research projects are another key element.

- There has been considerable discussion of the association between education and cognitive decline, and further research could usefully be directed towards correlations between factors such as baseline intelligence, level of education, health, and social class.

Once this information has been accrued one could envisage a multifactor intervention trial in normal healthy individuals, the interventions reflecting biological and behavioural rationale and with due knowledge of any possible toxicity. ${ }^{6}$

\section{References}

1 Morris JC, Storandt M, McKeel DW Jr, et al. Cerebral amyloid deposition and diffuse plaques in "normal" aging: evidence for presymptomatic and very mild Alzheimer's disease. Neurology 1996; 46: 707-19.

2 Morris JC, McKeel DW Jr, Storandt M, et al. Very mild Alzheimer's disease: informant based clinical psychometric, and pathologic distinction from normal aging. Neurology 1991; 41: 469-78.

3 Double KL, Halliday GM, Kril IJ, et al. Topography of brain atrophy during normal aging and Alzheimer's disease. Neurobiol Aging (in press).

4 Waite $\mathrm{L}$, Broe GA, Creasey $\mathrm{H}$, et al. Clinical diagnoses among community dwellers aged 75 or over. Arch Neurol (in press).

5 Padovani A, Di Piero V, Bragoni M, Iacoboni M, Gualdi GF, Lenzi GL Patterns of neuropsychological impairment in mild dementia: a comparison between Alzheimer's disease and multiinfarct dementia. Acta Neurol Scand 1995; 92: 433-42.

6 Hachinski V. Preventable senility: a call for action against the vascular dementias. Lancet 1992; 340: 645-48.

\section{Social aspects}

"More than the too excellent skills of the metaphysician, it is the dementias ... the breakdowns in mental skills which are really suited 'to reveal' us to ourselves."

\section{Henri Michaux}

In its advanced stages dementia sometimes seems a dehumanising disorder. It challenges our deepest preconceptions about human nature, the basis of consciousness, the freedom of the will, and personhood. Despite the work of philosophers and medical ethicists such as Harris (who defined a person as "a creature capable of valuing its own existence" ${ }^{2}$ ), a framework for a rational approach to the social, ethical, and legal aspects of the dementias still eludes us.

Dementia takes about 7 years to progress to the advanced stages, which is when the real challenges of dealing with a progressive, irreversible condition confront the carers at home and the medical carers. Caring for people with dementia includes caring for the carers. The features that cause stress in carers are wandering, aggression, repetitive questioning, sleep disturbance, incontinence, apathy, depression, pychosis, sexual disinhibition, and poor eating habits; ${ }^{3}$ these are seen in all cultures. The medical profession knows much about dementia and ways to help carers, but this knowledge needs to be applied in the community and passed on to the carers. Counselling, day care for the person with dementia, courses for carers, education, self-help groups, respite care, and inpatient admissions are ways of relieving the burden of caring for someone with dementia. These interventions could be complementary to but should not undermine the coping mechanisms (eg, accentuation of positive aspects, emphasis on moral duty) of the carer.

Intervention strategies and instruments to measure the level of stress and outcome of interventions are used with proven success in other domains of psychiatry, such as schizophrenia, and can be applied in dementia. They can be used to create more effective interventions to help carers to cope, such as community care programmes, which help to delay institutionalisation of the person with dementia, and improvement in the mental and physical health of carers. The success of these interventions can then be evaluated by the outcome measures (duration of caregiving, improvement in carer's health).

Although there is no effective treatment for people with dementia, clearly, there are reversible dementias (eg, hypothyroid) and many clinicians feel that even irreversible ones are treatable psychosocially. In the short-term more effective drugs for symptoms will probably appear, to be followed by more profound interventions to slow progression. However, we should clarify stage-specific therapeutic goals. Do we want to use drugs to enhance the thinking of persons with cognitive impairment, no dementia? Do we want to slow progression in an individual who can no longer recognise their spouse of 50 years? At the heart of our discussion of desirable treatment outcomes will be further consideration of the quality of life of both patients and carers. It is especially important that we develop ways to assess the quality of life of patients so as not to exclude them from input into their treatment plans. We must also look for new ways to be more effective in drug development.

Cognitive training early in the illness does seem to help, as assessed by quality of life measurements. A welcome spin-off is that their carers' quality of life also improves (figure).
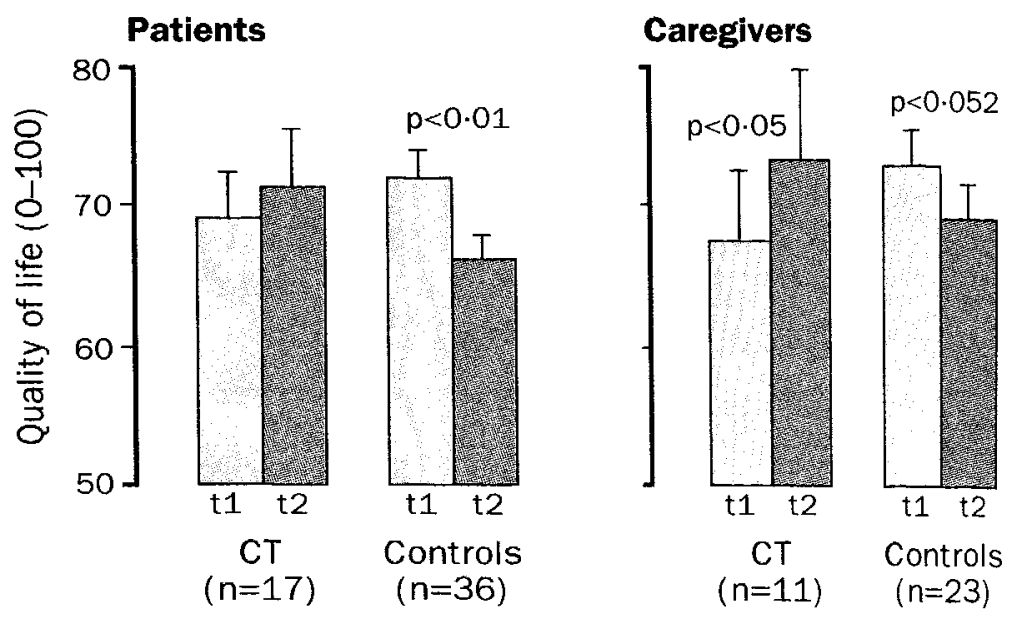

Figure: Effect of cognitive training on quality of life in people with dementia and their caregivers

$\mathrm{t} 1=$ baseline, $\mathrm{t} 2=12$ months later, $\mathrm{CT}=\mathrm{cog}$ nitive traınıng

(Presented at the conference by D Meier, Basel, Switzerland.) 
The pathologies causing age-associated cognitive decline are shown in panel 3. To regard these as mutually exclusive entities may make for tidy research projects but will do little for real understanding of brain impairment.

The first step for further research is to refine the tools that we already use. Thus:

- Neuropathological assessment should be based on standardised histological criteria. There is good reason for neuropathologists to devise such criteria "blind"-ie, without knowledge of clinical evaluation or results of imaging procedures.

- Similarly for neuropsychology, we need to understand the psychometric properties of the various tests that are commonly used. For example, what is the mini mental state examination really measuring?

- The neuroimaging net needs to be cast more widely to include all brain areas.

- Longitudinal neuropsychological and neuroimaging studies, with neuropathology, are critical, and interactive research projects are another key element.

- There has been considerable discussion of the association between education and cognitive decline, and further research could usefully be directed towards correlations between factors such as baseline intelligence, level of education, health, and social class.

Once this information has been accrued one could envisage a multifactor intervention trial in normal healthy individuals, the interventions reflecting biological and behavioural rationale and with due knowledge of any possible toxicity. ${ }^{6}$

\section{References}

1 Morris JC, Storandt M, McKeel DW Jr, et al. Cerebral amyloid deposition and diffuse plaques in "normal" aging: evidence for presymptomatic and very mild Alzheimer's disease. Neurology 1996; 46: 707-19.

2 Morris JC, McKeel DW Jr, Storandt M, et al. Very mild Alzheimer's disease: informant based clinical psychometric, and pathologic distinction from normal aging. Neurology 1991; 41: 469-78.

3 Double KL, Halliday GM, Kril IJ, et al. Topography of brain atrophy during normal aging and Alzheimer's disease. Neurobiol Aging (in press).

4 Waite $\mathrm{L}$, Broe GA, Creasey $\mathrm{H}$, et al. Clinical diagnoses among community dwellers aged 75 or over. Arch Neurol (in press).

5 Padovani A, Di Piero V, Bragoni M, Iacoboni M, Gualdi GF, Lenzi GL Patterns of neuropsychological impairment in mild dementia: a comparison between Alzheimer's disease and multiinfarct dementia. Acta Neurol Scand 1995; 92: 433-42.

6 Hachinski V. Preventable senility: a call for action against the vascular dementias. Lancet 1992; 340: 645-48.

\section{Social aspects}

"More than the too excellent skills of the metaphysician, it is the dementias ... the breakdowns in mental skills which are really suited 'to reveal' us to ourselves."

\section{Henri Michaux}

In its advanced stages dementia sometimes seems a dehumanising disorder. It challenges our deepest preconceptions about human nature, the basis of consciousness, the freedom of the will, and personhood. Despite the work of philosophers and medical ethicists such as Harris (who defined a person as "a creature capable of valuing its own existence" ${ }^{2}$ ), a framework for a rational approach to the social, ethical, and legal aspects of the dementias still eludes us.

Dementia takes about 7 years to progress to the advanced stages, which is when the real challenges of dealing with a progressive, irreversible condition confront the carers at home and the medical carers. Caring for people with dementia includes caring for the carers. The features that cause stress in carers are wandering, aggression, repetitive questioning, sleep disturbance, incontinence, apathy, depression, pychosis, sexual disinhibition, and poor eating habits; ${ }^{3}$ these are seen in all cultures. The medical profession knows much about dementia and ways to help carers, but this knowledge needs to be applied in the community and passed on to the carers. Counselling, day care for the person with dementia, courses for carers, education, self-help groups, respite care, and inpatient admissions are ways of relieving the burden of caring for someone with dementia. These interventions could be complementary to but should not undermine the coping mechanisms (eg, accentuation of positive aspects, emphasis on moral duty) of the carer.

Intervention strategies and instruments to measure the level of stress and outcome of interventions are used with proven success in other domains of psychiatry, such as schizophrenia, and can be applied in dementia. They can be used to create more effective interventions to help carers to cope, such as community care programmes, which help to delay institutionalisation of the person with dementia, and improvement in the mental and physical health of carers. The success of these interventions can then be evaluated by the outcome measures (duration of caregiving, improvement in carer's health).

Although there is no effective treatment for people with dementia, clearly, there are reversible dementias (eg, hypothyroid) and many clinicians feel that even irreversible ones are treatable psychosocially. In the short-term more effective drugs for symptoms will probably appear, to be followed by more profound interventions to slow progression. However, we should clarify stage-specific therapeutic goals. Do we want to use drugs to enhance the thinking of persons with cognitive impairment, no dementia? Do we want to slow progression in an individual who can no longer recognise their spouse of 50 years? At the heart of our discussion of desirable treatment outcomes will be further consideration of the quality of life of both patients and carers. It is especially important that we develop ways to assess the quality of life of patients so as not to exclude them from input into their treatment plans. We must also look for new ways to be more effective in drug development.

Cognitive training early in the illness does seem to help, as assessed by quality of life measurements. A welcome spin-off is that their carers' quality of life also improves (figure).
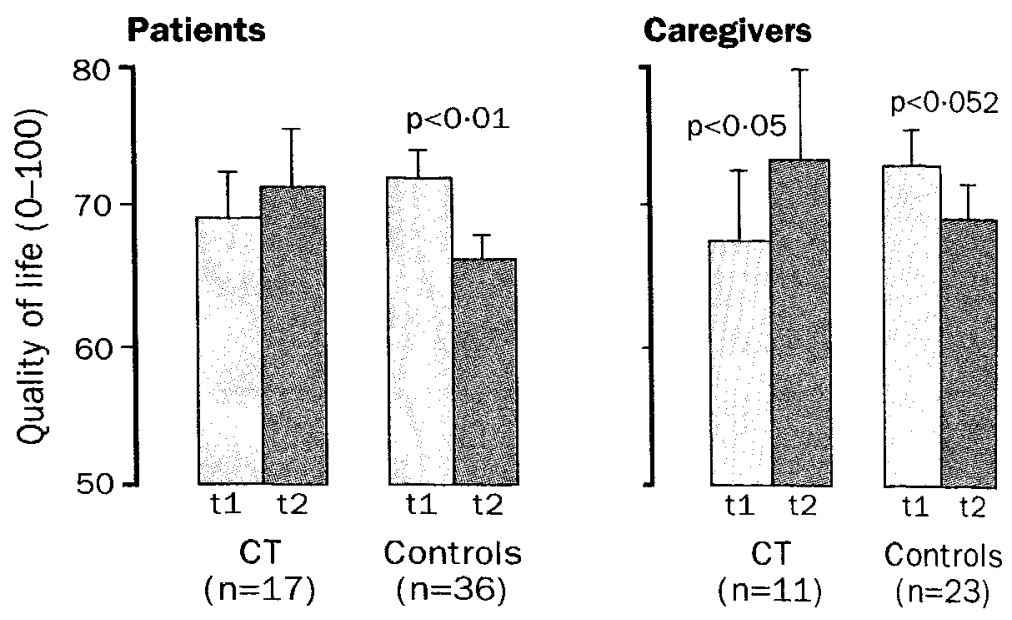

Figure: Effect of cognitive training on quality of life in people with dementia and their caregivers

$\mathrm{t} 1=$ baseline, $\mathrm{t} 2=12$ months later, $\mathrm{CT}=\mathrm{cog}$ nitive traınıng

(Presented at the conference by D Meier, Basel, Switzerland.) 
The issue of legal competence arises in dementiaespecially with respect to caring, treatment, and research. Legal capacity is specific to particular functions or tasks. There is a low legal threshold of competence to comply with medical care. Acceptance and rejection of medical advice are different functions, which creates a paradox. Patients who comply with treatment can enjoy the ordinary presumption of competence, whereas refusal of treatment will raise questions of competence. The law recognises competent individuals' rights to make bad choices, and those not competent cannot usually be managed by others in ways that they would have objected to when competent. Carers might have to enact poor choices in a person no longer competent. Consent to treatment can only be given by a person capable of giving it, but an incompetent person can assent (ie, not object) by being willing to let things happen.

There are legal strategies to address these issues. People can make plans when they are mildly demented. They can give directives for their personal care and treatment and to settle financial matters that will apply when they are more seriously affected. They can also approve someone to manage their care, treatment, and financial affairs in the future. And they can compose directives about participation in research trials. ${ }^{4}$

There is no uniform legal framework to cover the ethical issues and treatment in severe dementia. There are wide cultural differences with respect to communicating a diagnosis with a gloomy prognosis. If so informed, an individual can plan for the future if he is aware of the outlook, but in some countries doctors prefer to tell only the relatives the diagnosis, which raises issues about confidentiality. Another difficulty facing doctors is that of involving patients in treatment who are not competent to give informed consent. Here, in severe dementia, the treating physician is faced with a potential for conflict between people's autonomy and beneficence. Should a patient be given treatment to which he appears not to assent, even if it is in his perceived best interest? This conflict could be softened by encouraging individuals early in their illness to anticipate their incompetence and indicate what their wishes would be.

Questions of competence arise about participation in clinical trials and about treatment in dementia. In instances in which participation in clinical trials is judged worthwhile, should informed consent be obtained? Or should investigators withhold information, or inform unless there is a reason not to at the instigation of a trial? Should prior consent be obtained when individuals are competent, in the anticipation that they might take part in clinical trials later in their illness? Ethics committees vary greatly in their decisions, and there is huge local variation.
If tissue or blood samples have been obtained for one purpose, should consent be obtained for other investigations on those samples? Some investigators have circumvented this difficulty by obtaining permission to use samples in a particular area of research, rather than for a specific project.

Clearly, there is a need for guidelines about research participants' consent when competent and compliance when incompetent to participate in clinical trials, for proposed interventions, and for the use of tissues in research.

The issue of genetic testing in dementia is not clearcut. Little can be done therapeutically, so people cannot benefit in that way from knowledge of their genetic status. Legally, individuals are obliged to inform insurance companies of genetic test results, and their medical, life, and disability insurance cover might be affected by a positive result, which in any case can only be measured in terms of probability. In research, should an individual be informed of the result at the time or at some time in the future if such knowledge were appropriate at a later date (perhaps because of medical advances)? At present, generally, individuals are not informed, although some centres do so through the general practitioner. Perhaps we could learn from experience from other models, such as low-density lipoprotein testing and cholesterol. More informed public debate is needed with respect to genetic testing. Better relations between scientists and the media might help to ensure that reliable information is passed on to the public, especially the most important factor in the genetics of dementia - uncertainty.

\section{References}

1 Michaux $\mathrm{H}$. Infinite turbulence. Translated by Fineberg M. London: Calder and Boyars, 1975.

2 Harris J. Euthanasia and the value of life. In: Keown J, ed. Euthanasia examined: ethical, clinical and legal perspectives. Cambridge: Cambridge University Press, 1995: 9.

3 Allen $\mathrm{H}$, Burns A. The non-cognitive features of dementia. Rev Clin Gerontol 1995; 5: 57-75.

4 Dickens B. Substitute consent to participation of persons with Alzheimer's disease research: ethical and legal issues. In: Berg J, Karhinsky H, Lowy F, eds. Toronto: Carswell, 1990: 60-75.

Writing committee

Robin Eastwood (St Louis, MO, USA) (Chairman), Luigi Amaducc (Florence, Italy), Carol Brayne (Cambridge, UK), Tony Broe (Sydney, Australia), Alistair Burns (Manchester, UK), John Copeland (Liverpool, UK), Bernard Dickens (Toronto, Canada), Alison Goate (St Louis, MO, USA), Vladimir Hachinski (London, Ontario, Canada), Scott Henderson (Canberra, Australia), Jellemer Jolles (Maastricht, Netherlands), John Morris (St Louis, MO, USA), Karen Ritchie (Montpellier, France), Allen Roses (Durham, NC, USA), Martin Rossor (London, UK), Gerard Schellenberg (Seattle, WA, USA), Ingmar Skoog (Göteborg, Sweden), Martha Storandt (St Louis, MO, USA), Ray Tallis (Manchester, UK), and Peter Whitehouse (Cleveland, OH, USA); and Stephanie Clark, Imogen Evans, Richard Horton, and David Sharp (The Lancet, London, UK). 